\title{
A Study of Psychosocial Factors on Doctors Prescribing Behaviour - An Empirical Study in India
}

\author{
Dr. Neeti Kasliwal \\ Faculty of Management Studies, Banasthali Vidyapith, Jaipur Campus, India
}

\begin{abstract}
Prescribing behaviour is a dynamic and multifaceted process involving the intermediate customers who follow the norm of reciprocity as one of the fundamental guiding principle for taking decisions. The past studies have shown that the prescriber's decisions could depend upon factors from core aspects of drugs to their habitual aspects. The aim of the present study is to find out the impact of psychosocial factors on different age groups and different area of specialty of doctors in Rajasthan, India. A total of 431 doctors responses were gathered through a questionnaire method from different cities of Rajasthan. The results showed that the Paediatricians rated psychosocial (nonmedical) factors as least important factors influencing prescribing as compared to other specialties. Moreover senior doctors who are looked upon as KOL (key opinion leaders) to make rational prescribing decisions based on clinical facts also rated these psychosocial factors as less influencing as compared to younger doctors. The pharmaceutical marketing and doctors relationship is always a debate which raises not only ethical issues but also social issues. The findings of the study would be helpful to the pharmaceutical industry to curb any wasteful expenditure on the marketing of drugs to the doctors and indicate the factors that can act as a meaningful segmentation tool for the pharmaceutical marketers influencing the prescribing behaviour.
\end{abstract}

Keywords: Doctors prescribing behaviour, Doctors prescribing pattern, Non medical factorsPharmaceutical marketing, psychosocial factors

\section{Introduction}

Nothing can be taken for granted in today's marketing era. A marketer can succeed if they manage to create a difference. It is essential that a product has multiple reasons for being purchased which is different from other available products. And it becomes more challenging in the industry wherein the customer who takes decision is not the ultimate consumer. As in case of prescription drug market in India where the ultimate consumers (patients) have little say and are dependent upon the intermediate customers (doctors). It is estimated that India's $\$ 12$ billion drug market is growing 14 percent annually and companies are expected to triple sales forces by 2020 to capture this growing market [1]. Hence to sustain in this cut throat competitive business, a viable strategy is needed. The most important part of this strategy is to study the prescribing behaviour of the doctors which is seen as a cognitive activity wherein pros and cons of the behaviour are weighed before a drug choice is made.

\section{Review Of Literature}

Past studies have shown that the physicians' prescribing behaviour can be influenced and multiple factors are involved in physicians' decision to change their prescribing habits. (Hartzema et al 1983[2] identified non medical factors as important predictors of total prescribing volume among physicians. Armstrong et al 1996[3] revealed that factors like reading to involvement of professional colleagues were affecting GPs decision to change their prescribing behaviour. Waheed Abdul Kareem et al 2007[4] identified tangible rewards to doctors given by pharmaceutical companies, visits by PSR lead to physician loyalty to prescribe, Rahmer et al 2008[5] added new dimension to the prescribing process-the physicians patient relationship which was dominant factor in their study. Taneja Girish[6] studied the impact of promotional tools used by the pharmaceutical companies on different doctors revealed that private sector doctors attached more importance to personal seeling and educational promotional tools while DMs attached more importance to scientific promotional tools as compared to MD and PG Diploma doctors. Tan N C et al 2009[7] revealed the complexity of interrelated factors influencing Family Physicians (FPs) choice of drugs wherein CME programmes and detailing proved to be ineffective in influencing the FPs, Theodorou et al 2009[8] compared prescribing behaviour of physicians in Greece and Cyprus and found that Greek physicians were more likely to take additional criteria under consideration besides clinical effectiveness of drugs. Kotwani et al 2010[9] revealed the influence of medical representatives and inadequate knowledge in public sector doctors which led them to prescribe antibiotics in Delhi, Karayanni et al 2010[10] associated physicians personal values with prescribing criteria and marketing communications in the industry. Neyaz et al 2011[11] identified national and international differences in prescribing. Various studies have shown that doctors get influenced in their prescription behaviour due to 
factors like trust, or the quality image of the pharmaceutical manufacturer (Mohanty et al 2010[12]), prioritizing safety and efficacy over cost aspects while prescribing (Rahmner et al 2008[5]). A good number of studies have also concluded that the physicians have a positive attitude towards the pharmaceutical sales representatives (PSR) also known as MR (medical representatives) and they have an impact on the prescribing behaviour of the physicians (Caudill et 1996[13], Wazana 2000[14] concluded that doctors have positive attitude towards the interaction by the pharmaceutical companies which starts as early in medical school and till the practice lasts, Prosser T et al 2003[15] emphasised on the need for the doctors to reassess their relationship with the PSR who tend to influence the prescribing behaviour of the doctors. Watkins et al 2003[16], Chimonas et al 2007[17], also showed that the frequent contact with the PSR was significantly associated with the greater willingness to prescribe the new drugs. Lieb et al 2010[18] concluded that PSR visits influence doctors prescribing behaviour and while most doctors in the study done by Saito et al 2010[19] value the information they receive from the PSR. Both the studies also revealed that the doctors were less critical and found themselves less susceptible to any influence by the promotional activities than their colleagues. The studies investigating the effect of marketing tools and prescription behaviour have linked a positive correlation between the two (Girdharwal 2007[20], Jayakumar 2008[21], Stros et al 2009[22].

\section{Aims And Objectives Of The Study}

In the light of the above review of literature and the issues raised, the aim of the study was to determine what constituents the prescribing behaviour of the doctors and what was the level of importance given to the psychosocial factors by the doctors before their prescription choices. The study would answer the following research questions:

1. Which are the psychosocial factors that are deemed important for the doctors for making prescribing choices?

2. Are there any differences in prescribing behaviour of the doctors with reference to their demographic profiles?

To fulfill the above raised questions, following null hypothesis are proposed:

$\mathrm{HO}_{1}$ : There is no statistically significant impact of the psychosocial factors on prescribing behaviour among different age groups of doctors

$\mathrm{HO}_{2}$ : There is no statistically significant impact of the psychosocial factors on prescribing behaviour among different specialties of doctors

$\mathrm{HO}_{3}$ : There is no statistically significant impact of the psychosocial factors on prescribing behaviour between different genders of doctors

\section{Research Methodology}

For the purpose of the study, questionnaire was formulated and pretested for reliability and validity and necessary changes were incorporated to formulate a standardized questionnaire using Likert Scale which was then administered to 750 doctors of five different specialities namely, General Medicine, Gynaecology, Paediatrics, Ophthalmology and Psychiatry. The doctors were first contacted through telephone and permission was taken to post the questionnaire. The list of the doctors and their telephone numbers were taken from Rajasthan Medical Directory. A covering letter was sent along with a self stamped envelope with each questionnaire. No incentives of any form were given for completing the questionnaire. Non respondents were again contacted by telephone and emails and were encouraged to participate.

First part of questionnaire was designed to obtain the demographic information and profile of the doctors. Second part of the questionnaire was focussing on the psychosocial factors identified from the literature review which affect the prescribing behaviour of the doctors. The doctors gave their responses for those factors with respect to the importance attached to each factor. Mean scores was calculated by allocating values of 1 , $2,3,4,5$ respectively to the responses. A lower score indicated that a particular factor was less influencing as compared factor with higher score. The data collected through the questionnaire schedule was coded and tabulated keeping in context the objectives of the study.

The data was collected from December 2011till April 2012 and the statistical tools used were frequency distribution, ANOVA and Z-test for analysis. A total of 431 doctors responses were drawn making a response rate of $57.46 \%$ from 26 different towns and cities of Rajasthan namely Ajmer, Alwar, Baswara, Beawar, Bharatpur, Bhilwara, Bikaner, Bundi, Chittorgarh, Dausa, Dholpur, Hanumangarh, Jaipur, Jhalawara, Jhunjhunu, Jodhpur, Kishangarh, Kota, Mt.Abu, Nagaur, Pali, Rajsamand, Sikar, Sriganganagar, Swaimadhopur, Tonk, Udaipur. 
DEMOGRAPHIC PROFILE

\section{Results And Findings}

As depicted in TABLE I, out of 431 doctors 344 were males constituting $80 \%$ of the sample and 87 were females, constituting $20 \%$ of the sample. The number of doctors in the study who belonged to the age group of 25-35 years of age were 15(4\%), while 36-40 years of age of doctors were 35(8\%), 41-45 years of age of doctors were 53(12\%), while 46-50 years of age group of doctors were 71(16\%), 51-60 years of age of doctors were $158(37 \%)$ while 61 and above years of age of doctors were $99(23 \%)$ respectively. The number of doctors who were General Physicians was 198(46\%) which is the majority of the sample pertaining to area of specialty while Gynecologists/ Obstetricians was 80 (18.5\%); Pediatricians 80 (18.5\%), Ophthalmologists 61 (14\%) and Psychiatrists were $12(3 \%)$ respectively.

TABLE I: Descriptive statistics of the sample

\begin{tabular}{|c|c|c|c|c|c|c|}
\hline & \multicolumn{6}{|c|}{ Gender } \\
\hline & \multicolumn{3}{|c|}{$M$} & \multicolumn{3}{|c|}{$F$} \\
\hline Total & \multicolumn{3}{|c|}{344} & \multicolumn{3}{|c|}{87} \\
\hline \multirow[t]{3}{*}{ \%age } & \multicolumn{2}{|r|}{80} & & \multicolumn{3}{|c|}{20} \\
\hline & \multicolumn{6}{|c|}{ Specialty } \\
\hline & GPs & Gynaecology & Paediatrics & Oph & hology & Psychiatry \\
\hline Total & 198 & 80 & 80 & & & 12 \\
\hline \multirow[t]{3}{*}{ \%age } & 46 & 18.5 & 18.5 & & & 3 \\
\hline & \multicolumn{6}{|c|}{ Age in years } \\
\hline & $25-35$ & $36-40$ & $41-45$ & $46-50$ & $51-60$ & 61 \&above \\
\hline Total & 15 & 35 & 53 & 71 & 158 & 99 \\
\hline \%age & 4 & 8 & 12 & 16 & 37 & 23 \\
\hline
\end{tabular}

Source: Authors own

Further various statistical tests of significance which have been used for testing of hypotheses related to the differences in the importance attached by doctors relating to psychosocial factors were calculated. The results obtained from ANOVA showed that the variations could be attributed to various demographic profiles of the doctors and were statistically significant. Hence $Z$ test was conducted to test the hypotheses to know which particular sub group of demographic profile of the doctors was influenced by the psychosocial factors.

\section{Z Test Results}

As seen in TABLE II, the impact of psychosocial factors among young doctors prescribing behaviour has been more as compared to other age group of doctors. Also senior doctors in the age group of 41-45 years of age are KOL (key opinion leaders) because of their experience in the profession are looked upon for advice and are role models, rated these psychosocial factors less important and were less influenced by them when it comes to making drug choices. Hence $\mathrm{HO}_{1}$ which stated that there is no statistically significant impact of the psychosocial factors on prescribing behaviour among different age groups of doctors is rejected.

TABLE II: Impact of Psychosocial Factors among Different Age Groups of Doctors

\begin{tabular}{|c|c|c|c|c|c|}
\hline Psychosocial factors & $\begin{array}{c}\text { Sample } \\
\text { Criterion }\end{array}$ & $\mathrm{N}$ & Mean & S.D. & $\begin{array}{l}Z \\
\text { value }\end{array}$ \\
\hline \multirow{2}{*}{ Peer group advice } & $\begin{array}{c}\text { AGE (25 to35 } \\
\text { years) }\end{array}$ & 15 & 3.93 & 0.593 & \multirow{2}{*}{$3.43 * *$} \\
\hline & $\mathrm{AGE}<>1$ & 416 & 3.38 & 0.905 & \\
\hline \multirow[t]{2}{*}{ Rapport of MR } & $\begin{array}{c}\text { AGE(41 to } 45 \\
\text { yrs) }\end{array}$ & 53 & 2.3 & 1.066 & \multirow[t]{2}{*}{$-2.4 *$} \\
\hline & $\mathrm{AGE}<>3$ & 378 & 2.68 & 1.033 & \\
\hline \multirow[t]{2}{*}{ MR's personality traits } & $\begin{array}{c}\text { AGE(41 to } 45 \\
\text { yrs) }\end{array}$ & 53 & 2.49 & 1.085 & \multirow[t]{2}{*}{$-2.32 *$} \\
\hline & $\mathrm{AGE}<>3$ & 378 & 2.87 & 1.176 & \\
\hline \multirow{4}{*}{$\begin{array}{l}\text { MR's product } \\
\text { knowledge }\end{array}$} & $\begin{array}{c}\text { AGE (25 to35 } \\
\text { years) }\end{array}$ & 15 & 3.93 & 1.099 & \multirow[t]{2}{*}{$2.51 *$} \\
\hline & $\mathrm{AGE}<>1$ & 416 & 3.2 & 1.229 & \\
\hline & $\begin{array}{c}\text { AGE(41 to } 45 \\
\text { yrs) }\end{array}$ & 53 & 2.89 & 1.25 & \multirow[t]{2}{*}{$-2.13 *$} \\
\hline & $\mathrm{AGE}<>3$ & 378 & 3.28 & 1.222 & \\
\hline \multirow{2}{*}{$\begin{array}{l}\text { Physicians free } \\
\text { samples }\end{array}$} & $\begin{array}{c}\text { AGE (25 to35 } \\
\text { years) }\end{array}$ & 15 & 2.73 & 1.099 & \multirow[t]{2}{*}{$2.23 *$} \\
\hline & $\mathrm{AGE}<>1$ & 416 & 2.09 & 1.066 & \\
\hline \multirow{3}{*}{$\begin{array}{l}\text { Distribution of leaflets } \\
\text { and brochures }\end{array}$} & $\begin{array}{c}\text { AGE(41 to } 45 \\
\text { yrs) }\end{array}$ & 53 & 2.08 & 1.089 & \multirow[t]{2}{*}{$-3.69 * *$} \\
\hline & $\mathrm{AGE}<>3$ & 378 & 2.67 & 1.135 & \\
\hline & $\begin{array}{c}\mathrm{AGE}(61 \mathrm{yrs} \\
\text { \&above) }\end{array}$ & 99 & 2.87 & 1.157 & $2.68 * *$ \\
\hline
\end{tabular}




\begin{tabular}{|c|c|c|c|c|c|}
\hline & AGE $<>6$ & 332 & 2.52 & 1.13 & \\
\hline $\begin{array}{c}\text { Colleagues as source } \\
\text { of information of new } \\
\text { drugs }\end{array}$ & $\begin{array}{c}\text { AGE }(25 \text { to } 35 \\
\text { years })\end{array}$ & 15 & 3.93 & 0.258 & \multirow{2}{*}{$2.72 * *$} \\
\cline { 2 - 5 } & AGE $<>1$ & 416 & 3.72 & 0.781 & \\
\hline \multicolumn{6}{|c|}{$* \mathrm{P}<.05 ; * * \mathrm{P}<.01$} \\
\hline
\end{tabular}

As seen TABLE III, the importance attached to the psychosocial factors while prescribing a drug has been less on different specialties of doctors except in case of Psychiatrists who rated high importance to MR's personality traits in their prescription choices, Ophthalmologists who rated colleagues as a source of information of new drugs as more important factor as compared to other specialties and Gynaecologists who considered MR as a source of information of new drugs as important factor which is contrary to prior studies where MR's information is perceived by doctors as untrue and inaccurate. It can also be seen from the table that Paediatricians were least influenced by the psychosocial factors which led them to make more rational decisions before prescribing a drug. Hence $\mathrm{HO}_{2}$ which stated that there is no statistically significant impact of the psychosocial factors on prescribing behaviour among different specialties of doctors is rejected as significant differences were found among different specialities of doctors.

TABLE III: Impact of Psychosocial Factors among Different Specialties of Doctors

\begin{tabular}{|c|c|c|c|c|c|}
\hline Psychosocial factors & Sample Criterion & $\mathrm{N}$ & Mean & S.D. & $Z$ value \\
\hline \multirow{4}{*}{ Rapport of MR } & SPCD=1(G.P.) & 198 & 2.78 & 1.021 & \multirow{2}{*}{$-2.81 * *$} \\
\hline & $\mathrm{SPCD}<>1$ & 233 & 2.5 & 1.046 & \\
\hline & $\mathrm{SPCD}=3(\mathrm{Paed})$ & 80 & 2.4 & 1.142 & $-2.04 *$ \\
\hline & $\mathrm{SPCD}<>3$ & 351 & 2.68 & 1.014 & \\
\hline \multirow{4}{*}{$\begin{array}{l}\text { MR's personality } \\
\text { traits }\end{array}$} & $\mathrm{SPCD}=3(\mathrm{Paed})$ & 80 & 2.58 & 1.155 & \multirow[t]{2}{*}{$-2.08 *$} \\
\hline & $\mathrm{SPCD}<>3$ & 351 & 2.87 & 1.169 & \\
\hline & SPCD $=5$ (Psychiatry) & 12 & 3.67 & 1.154 & $2.57 * *$ \\
\hline & $\mathrm{SPCD}<>5$ & 419 & 2.79 & 1.164 & \multirow{3}{*}{$-2.07^{*}$} \\
\hline \multirow{2}{*}{$\begin{array}{l}\text { MR's } \quad \text { product } \\
\text { knowledge }\end{array}$} & $\mathrm{SPCD}=3($ Paed $)$ & 80 & 2.98 & 1.211 & \\
\hline & $\mathrm{SPCD}<>3$ & 351 & 3.29 & 1.23 & \\
\hline \multirow{2}{*}{$\begin{array}{ll}\text { Physicians } & \text { free } \\
\text { samples } & \end{array}$} & $\mathrm{SPCD}=3(\mathrm{Paed})$ & 80 & 1.79 & 0.923 & \multirow{2}{*}{$-3.35 * *$} \\
\hline & $\mathrm{SPCD}<>3$ & 351 & 2.19 & 1.091 & \\
\hline \multirow{2}{*}{$\begin{array}{ll}\text { Distribution } & \text { of } \\
\text { leaflets brochures } & \end{array}$} & $\mathrm{SPCD}=3$ (Paed) & 80 & 2.17 & 1.111 & \multirow[b]{2}{*}{$-3.74 * *$} \\
\hline & $\mathrm{SPCD}<>3$ & 351 & 2.69 & 1.132 & \\
\hline \multirow{2}{*}{$\begin{array}{l}\text { CME/ Academic } \\
\text { sponsorships }\end{array}$} & $\mathrm{SPCD}=3(\mathrm{Paed})$ & 80 & 2.54 & 1.179 & \multirow[t]{2}{*}{$-2.19 *$} \\
\hline & $\mathrm{SPCD}<>3$ & 351 & 2.86 & 1.174 & \\
\hline \multirow{2}{*}{$\begin{array}{l}\text { Colleagues as source } \\
\text { of information of new } \\
\text { drugs }\end{array}$} & $\mathrm{SPCD}=4$ (Opth.) & 61 & 3.93 & 0.749 & \multirow{2}{*}{$2.28 *$} \\
\hline & $\mathrm{SPCD}<>4$ & 370 & 3.7 & 0.768 & \\
\hline \multirow{2}{*}{$\begin{array}{l}\text { MR as a source of } \\
\text { information of new } \\
\text { drugs }\end{array}$} & $\mathrm{SPCD}=2($ Gyne/Obst $)$ & 80 & 3.83 & 0.807 & $2.8^{* *}$ \\
\hline & $\mathrm{SPCD}<>2$ & 351 & 3.53 & 1.044 & \\
\hline
\end{tabular}

TABLE IV shows the importance attached to the psychosocial factors (like MR's product knowledge and MR as a source of information of new drugs) on prescribing behaviour of male doctors was found to be less as compared to female doctors. For the rest of the factors the gender did not show variation in getting influenced by the psychosocial factors. Hence the $\mathrm{HO}_{3}$ which stated that there is no statistically significant impact of the psychosocial factors on prescribing behaviour between different genders of doctors is rejected.

TABLE IV: Impact of Psychosocial Factors between Different Genders of Doctors

\begin{tabular}{|c|l|c|c|c|c|}
\hline Psychosocial factors & Sample Criterion & $\mathrm{N}$ & Mean & S.D. & Z value \\
\hline \multirow{2}{*}{$\begin{array}{c}\text { MR as a source of information } \\
\text { of new drugs }\end{array}$} & $\begin{array}{l}\text { GENDER1 } \\
\text { (Male) }\end{array}$ & 344 & 3.52 & 1.046 & $-2.81^{* *}$ \\
\cline { 2 - 6 } & $\begin{array}{l}\text { GENDER2 } \\
\text { (Female) }\end{array}$ & 87 & 3.82 & 0.814 & \\
\hline \multirow{2}{*}{ MR's product knowledge } & $\begin{array}{l}\text { GENDER1 } \\
\text { (Male) }\end{array}$ & 344 & 3.17 & 1.237 & $-2.00^{*}$ \\
\cline { 2 - 6 } & $\begin{array}{l}\text { GENDER2 } \\
\text { (Female) }\end{array}$ & 87 & 3.46 & 1.189 & \\
\hline
\end{tabular}

$* \mathrm{P}<.05 ; * * \mathrm{P}<.01$ 


\section{Discussion}

This present study adds to the previous research that conceptualizes the fact that clinical practice decision making is a dynamic process which is affected by number of factors (Prosser et al 2003[15]) and that the decisions could depend upon factors from core aspects of drug, contextual aspect and habitual aspect (Denig et al 2002[23]). Although the pharmacological criteria is generally used by the doctors in deciding which drug to prescribe, the findings of the study shows that the psychosocial influences are also rated important factors in the doctors decision to prescribe. The present study also indentified the influence of doctors' characteristics on prescribing behaviour and analyzed that the demographic variables like gender of the doctors, age of doctors and specialty of the doctors have an impact of their prescribing behaviour. Previous studies have focused on identifying the factors that influence physicians prescribing behaviour and have determined that unobservable physicians' attributes are strong determinants of prescribing behaviour (Rice Jennifer, 2012[24]). The variations in doctors prescribing behaviour in the study goes in line with the this study and also study done by Martin as quoted in Hartzema et al. 1983[2] which concluded that the major determinant of differences in the prescribing was because of the "psychological climate with which all prescription tales place" which are the non medical factors influencing the prescribing behaviour. These non medical factors are primarily the individual factors affecting the doctors prescribing behaviour and marketing initiatives taken by the companies to affect prescribing pattern.

In emerging markets like India, where doctors are considered nothing less than Gods, influencing their prescribing behaviour is the key for every pharmaceutical company. The past studies have shown that the prescribing behaviour can be influenced and doctors respond to different types of cues to change their prescribing pattern (Armstrong et al. 1996[3]). The present study identified these cues and doctors in the study responded to these cues differently. Campbell et al. 2007[25] identified that physicians' relationships with the industry vary according to physicians' personal and professional characteristics and according to the practice setting as seen in the present study where doctors of different age groups, specialty, and gender showed variations in prescribing behaviour with respect to pharmaceutical industry interactions.

\section{Conclusions}

Pharmaceutical companies in India are directing all their marketing efforts towards doctors as they have the choice of the drug and the brands to prescribe. Doctors play a pivotal role in influencing their patients' pattern of selecting and administering drugs. As a result, even the information about products and brands has been restricted to doctors and other healthcare professionals. The present study has highlighted the factors influencing the doctors prescribing behaviour and concludes that the prescribing behaviour is a complex activity involving interplay of number of factors which varies from medical to psychosocial factors which are also rated important criteria in the doctors' decision to prescribe. The study reveals that the impact of these psychosocial factors varies across different demographic characteristics of the doctors and the young doctors are more influenced by them as compared to the senior doctors. The study results would provide a framework to the pharmaceutical managers to segment and target different profiles of doctors according to their demographic profiles and avoid any wasteful expenditure, time and effort in interacting with their prospective intermediate customers.

The study of pharmaceutical marketing in India is at a nascent stage and there lies immense scope in this field. The researcher has identified some of the areas which were not touched upon in the current study would further enhance the results of the present study. The prescribing behaviour of rural sector doctors can give a new insight about this untapped market to the pharmaceutical managers. The future scope also extends to the use of combination of qualitative approach with quantitative approach in studying the doctors prescribing behaviour. Future studies can take more specialities' and pan Indian study can be conducted to have an overall knowledge of what doctors thins before prescribing a drug.

\section{Acknowledgement}

The author wishes to acknowledge Dr. Aparna Bhatia, Lecturer, Guru Nanak Dev University Amritsar, for her kind guidance and support. The author also wishes to thank Raj Kumar for statistical inputs.

\section{References}

[1]. (2010) GOI website. [Online]. Available at http://www.pharmaceuticals.gov.in/

[2]. Hartzema Abhraham, Christensen Dale, Nonmedical Factors Associated with Prescribing Volume among Family Practitioners in an HMO, Medical care, 21 (10), 1983, 990-1000.

[3]. Armstrong David, Reyburn Hugh, Jones Roger, A Study of General Practitioners Reasons For Changing Their Prescribing Behavior, BMJ, 312, (l), 1996, 949-952.

[4]. Waheed Abdul Kareem, Jaleel Mohammad, Laeequddin Mohammad, Prescription Loyalty Behaviour of Physicians: An Empirical Study in India, International Journal Of Pharmaceutical and Healthcare Marketing, 5(4), 2007, 279-298.

[5]. Rahmner Bastholm, Gustafsson Lars, Larsson Jan, Rosenqvist Urban, Tomson Goran, Holmstrom Inger, Variations in Understanding the Drug Prescribing Process: A Qualitative Study among Swedish GP's, Family Practice, 26, 2008, 121-127 
[6]. Taneja Girish, Impact of Pharmaceutical Industry Promotion Mix on Doctors Prescribing Behaviour, Asia-Pacific Business Review, 4, 2008,13-18

[7]. Tan N C, Tay I H, Ngoh A, Tan M, Factors Influencing Family Physicians' Drug Prescribing Behavior in Asthma Management in Primary Care, Singapore Medical Journal, 50(3), 2009, 312-319

[8]. Theodorou Mamas, Vasiliki Tsiantou, Andreas Pavlakis, Nikos Maniadakis, Vasilis Fragoulakis, Elpida Pavi And John Kyriopoulos, Factors Influencing Prescribing Behavior of Physicians In Greece And Cyprus: Results From A Questionnaire Based Survey, BMC Health Services Research, 9, 2009,50 Doi:10.1186/1472-6963-9-150

[9]. Kotwani Anita, Wattal Chand, Katewa Shashi, Joshi PC, Holloway Kathleen ,Factors Influencing Primary Care Physicians To Prescribe Antibiotics in Delhi India, Family Practice, 27, 2010,684-690

[10]. Karayanni D, A Cluster Analysis of Physicians Values, Prescribing Behavior and Attitudes towards Firm Marketing Communications, International Journal of Customer Relationship Marketing and Management, 2010, 3-26

[11]. Neyaz Y, Qureshi NA, Khoja T, Magzoub MA, Haycox A, Walley T, Physicians' Medication Prescribing In Primary Care In Riyadh City, Saudi Arabia. Literature Review, Part 1: Variations In Drug Prescribing, Eastern Mediterranean Health Journal, 17(2), 2011, $126-131$

[12]. Mohanty BK, Aswini M, Hasamnis AA, Patil SS, Murty KSK, Jena SK, Prescription Pattern In The Department Of Medicine Of A Tertiary Care Hospital In South India, Journal of Clinical and Diagnostic Research, 3, 2010, 2047-2051

[13]. Caudill TS, Johnson MS, Rich EC, McKinney WP, Physicians, Pharmaceutical Sales Representatives, and the Cost of Prescribing, Arch Family Medicine, 5, 1996, 201-206

[14]. Wazana, A, Doctors and the Pharmaceutical Industry Is A Gift Ever Just A Gift? Journal of American Medical Association, 283, 2000, 373-380

[15]. Prosser H, Walley T, Understanding Why GP's See Pharmaceutical Representatives: A Qualitative Interview Study, British Journal of General Practice, 53,2003, 305-311

[16]. Watkins Chris, Laurence Moore, Ian Harvey, Patricia Carthy, Elizabeth Robinson, and Richard Brawn, Attitudes and Behavior of General Practitioners and Their Prescribing Costs: A National Cross Sectional Survey, Quality Safety Health Care, 12, 2003, 29-34

[17]. Chimonas Susan, Brennan Troyen, Rothman David, Physicians and Drug Representatives: Exploring the Dynamics of The Relationship, Society Of General Internal Medicine, 22, 2007, 184-190

[18]. Lieb Klaus, Simone Brandtönies, A Survey of German Physicians in Private Practice about Contacts with Pharmaceutical Sales Representatives, Deutsches Ärzteblatt International | Dtsch Arztebl Int 107(22) (2004): 392-398

[19]. Saito Sayaka, Mukohara Kie, Bito Seiji, Japanese Practicing Physicians' Relationships with Pharmaceutical Representatives: A National Survey, Plos One, 5, 2010 Doi: 10.1371

[20]. Girdharwal Nitin, A Study of Physicians' Behavior towards Marketing of Pharmaceutical Products: A Case Study of Indian Market, pharmainfo.net, November 2007, retrieved on 5/5/2011

[21]. Jayakumar P.B, Drug Firms May Stop Freebies to Doctors, Business Standard, 22nd July 2008, pp 4

[22]. Stros Michael, Hari Juerg, Marriott John, The Relevance of Marketing Activities in The Swiss Prescribing Drugs Market: Two Empirical Studies, International Journal Of Pharmaceutical And Healthcare Marketing, 3(4), 2009, 323-346

[23]. Denig P, Witteman C L M, Schouten H W, Scope and nature of prescribing decisions made by general practitioners, Quality Safety Health Care, 2002, 11, 137-143

[24]. Rice L Jennifer, The influence of Managed Care on Generic Prescribing rates: An Analysis of HMO Physicians, Applied Economics, 43:7, 2011,787-796

[25]. Campbell Eric G, Gruen Russel 1, Mountford James, Miller Lawrence, Cleary Paul, Blumenthal David, A National Survey Of Physician-Industry Relationships, The New England Journal of Medicine, 356(17), 2007, 1742-1750 